\title{
Micro-organismos da subclasse coccidia: resistência e implicações para o processamento de materiais de assistência à saúde
}

\author{
MICROORGANISMS OF THE COCCIDIA SUBCLASS: RESISTANCE AND IMPLICATIONS \\ FOR THE ASEPTIC PROCESSING OF HEALTHCARE PRODUCTS
}

\section{MICROORGANISMOS DE LA SUBCLASE COCCIDIA: RESISTENCIA E IMPLICANCIAS PARA EL PROCESAMIENTO DE MATERIALES DE ATENCIÓN A LA SALUD}

\section{Rafael Queiroz de Souza', Lilian Machado Torres², Kazuko Uchikawa Graziano², Ruth Natália Teresa Turrini ${ }^{4}$}

\section{RESUMO}

Este estudo teórico propõe uma reflexão sobre a resistência intrínseca da subclasse Coccidia, particularmente o gênero Cryptosporidium, considerado como um agente potencialmente patogênico para pacientes imunocomprometidos, e suas repercussões na prática assistencial. Atualmente, as diretrizes internacionais e nacionais aprovam como procedimento seguro a desinfecção química de alto nível de endoscópios digestivos, após sua limpeza. No entanto, estudos evidenciaram que micro-organismos da subclasse Coccidia, especificamente o Cryptosporidium, responsável por infecção entérica, são mais resistentes que as micobactérias e não são inativados pelos desinfetantes químicos de alto nível, exceto pelo Peróxido de Hidrogênio a $6 \%$ e 7,5\%, formulação ainda não disponível no Brasil. Conclui-se que a legislação deve incluir este agente entre os micro-organismos teste para aprovação de desinfetantes químicos de alto nível e que as autoridades sanitárias devem se esforçar para garantir que os estabelecimentos de assistência à saúde tenham acesso a produtos eficazes contra o Cryptosporidium.

\section{DESCRITORES}

Desinfecção

Endoscópios

Infecção hospitalar

Coccídios

Hospedeiro imunocomprometido

\begin{abstract}
This theoretical study proposes a reflection on the intrinsic resistance of the subclass Coccidia, particularly the genus Cryptosporidium, considered to be potential pathogens for immunocompromised patients, and the implications for nursing practice. Currently, the international and national guidelines support the chemical disinfection of digestive system endoscopes after their cleansing as a safe and effective procedure. However, studies show that microorganisms of the subclass Coccidia, namely Cryptosporidium, responsible for enteric infection, are more resistant than mycobacteria and are not inactivated by highlevel disinfectants, except for hydrogen peroxide $6 \%$ and $7.5 \%$, which are not currently available in Brazil. We conclude that the legislation should include this agent among test microorganisms for approving high-level disinfectants. Health authorities should make efforts to ensure that healthcare institutions have access to effective disinfectants against Cryptosporidium.
\end{abstract}

DESCRIPTORS
Disinfection
Endoscopes
Cross infection
Coccidia
Immunocompromised host

\section{RESUMEN}

Estudio teórico que propone reflexión sobre la resistencia intrínseca de la subclase $\mathrm{Coc}$ cidia, particularmente el género Cryptosporidium, considerado agente potencialmente patogénico para pacientes inmunocomprometidos, y sus repercusiones para práctica asistencial. Actualmente, las normativas internacionales y nacionales aprueban como procedimiento seguro la desinfección química de alto nivel de endoscopios digestivos, luego de su limpieza. Mientras tanto, los estudios evidenciaron que microorganismos de subclase Coccidia, específicamente el Cryptosporidium, responsable por infección entérica, son más resistentes que las microbacterias y no son inactivados por desinfectantes químicos de alto nivel, excepto el Peróxido de Hidrógeno a $6 \%$ y $7,5 \%$, formulación aún no disponible en Brasil. Se concluye en que la legislación debe incluir este agente entre los microorganismos de prueba para aprobación de desinfectantes químicos de alto nivel y que las autoridades sanitarias deben esforzarse para que los Establecimientos de Atención de Salud tengan acceso a productos eficaces contra el Cryptosporidium.

\author{
DESCRIPTORES \\ Desinfección \\ Endoscopios \\ Infección hospitalaria \\ Coccidios \\ Húesped inmunocomprometido
}

\footnotetext{
${ }^{1}$ Enfermeiro. Doutorando pelo Programa de Pós-Graduação em Enfermagem na Saúde do Adulto da Escola de Enfermagem da Universidade de São Paulo. São Paulo, SP, Brasil. rafaelqsouza@hotmail.com ${ }^{2}$ Enfermeira. Mestranda pelo Programa de Pós-Graduação em Enfermagem na Saúde do Adulto da Escola de Enfermagem da Universidade de São Paulo. Especialista em Epidemiologia do Controle de Infecções Hospitalares. Belo Horizonte, MG, Brasil. lilian.torres@ipsemg.mg.gov.br ${ }^{3}$ Enfermeira. Professora Titular do Departamento de Enfermagem Médico-Cirúrgica da Escola de Enfermagem da Universidade de São Paulo. São Paulo, SP, Brasil. kugrazia@usp.br ${ }^{4}$ Enfermeira. Professora Doutora do Departamento de Enfermagem Médico-Cirúrgica da Escola de Enfermagem da Universidade de São Paulo. São Paulo, SP, Brasil. rturrini@usp.br
} 


\section{INTRODUÇÃO}

Em $1968^{(1)}$, a ação biocida dos desinfetantes químicos utilizados em materiais de assistência à saúde foi classificada de acordo com a resistência intrínseca dos micro-organismos. Conforme a classificação, para uma desinfecção química de alto nível, o efeito biocida deve se estender aos bacilos da tuberculose, bactérias vegetativas, vírus de tamanho médio e lipídicos, vírus pequenos e não lipídicos e a maioria dos micro-organismos na forma esporulada. Para uma desinfecção química de nível intermediário, o efeito não abrange os esporos e, em uma desinfecção química de baixo nível, a ação biocida é restrita às bactérias vegetativas e aos vírus médios e lipídicos.

Anos mais tarde, a ação biocida dos desinfetantes químicos foi melhor especificada ${ }^{(2)}$ e passou a ser descri- ta com base no elemento mais resistente de cada grupo de micro-organismos: esporos bacterianos (B. subtilis), micobactérias ( $M$. tuberculosis), vírus pequenos ou não lipídicos (Poliovírus), fungos (Candida spp), bactérias vegetativas ( $P$. aeruginosa), vírus médios ou lipídicos (vírus da hepatite B -HBV). Esta classificação vem subsidiando os profissionais de saúde até os dias atuais na decisão sobre a escolha de desinfetantes para materiais utilizados na assistência à saúde.

No entanto, no decorrer do tempo, novos agentes e partículas protéicas infecciosas foram destacados como de importância na epidemiologia das doenças transmissíveis e, frente a evidências científicas da resistência de alguns, a ordem de resistência dos micro-organismos a agentes químicos desinfetantes de alto nível inicialmente proposta em 1968 e revista em 1991, sofreu alterações em $1999^{(3)}$ e em $2008^{(4)}$. Estas duas novas propostas estão apresentadas no Quadro 1.

Quadro 1 - Ordem de resistência dos micro-organismos a agentes químicos desinfetantes de alto nível segundo os autores

\begin{tabular}{|c|c|}
\hline Proposta I - McDonnel e Russel,1999* & Proposta II - Rutala e Weber, 2008** \\
\hline Prions & Prions \\
\hline$\downarrow$ & $\downarrow$ \\
\hline Coccidia (Cryptosporidium) & Esporos bacterianos (Bacillus atrophaeus) \\
\hline$\downarrow$ & $\downarrow$ \\
\hline Esporos (Bacillus spp., Clostridium difficile) & Coccidia (Cryptosporidium) \\
\hline$\downarrow$ & $\downarrow$ \\
\hline Micobactérias (M. tuberculosis, M. avium) & Micobactérias (M. tuberculosis, M. terrae) \\
\hline$\downarrow$ & $\downarrow$ \\
\hline Cistos (Giardia, Tênia solium, Tênia sarginata) & Vírus pequenos ou não lipídicos (pólio, coxsackie) \\
\hline$\downarrow$ & $\downarrow$ \\
\hline Vírus pequenos não envelopados (pólio) & Fungos (Aspergillus, Candida spp.) \\
\hline$\downarrow$ & $\downarrow$ \\
\hline Trofozoítas (Acanthamoeba, Trypanossoma cruzii) & Bactérias vegetativas ( $S$. aureus, $P$. aeruginosa) \\
\hline $\begin{array}{c}\text { Bactérias Gram negativas (Pseudomonas spp., Escherichia coli, } \\
\text { Serratia } \text { spp., Providencia) }\end{array}$ & Vírus médios ou lipídicos (HIV, herpes,HBV) \\
\hline \multicolumn{2}{|l|}{$\downarrow$} \\
\hline \multicolumn{2}{|l|}{ Fungos (Candida spp., Aspergillus spp.) } \\
\hline \multicolumn{2}{|l|}{$\downarrow$} \\
\hline \multicolumn{2}{|l|}{ Vírus grandes não envelopados (Adenovirus) } \\
\hline \multirow{2}{*}{\multicolumn{2}{|c|}{$\begin{array}{c}\downarrow \\
\text { Bactérias Gram positivas (Staphylococcus spp., Enterococos spp.) }\end{array}$}} \\
\hline & \\
\hline$\downarrow$ & \\
\hline Vírus lipídicos envelopados (HIV, HBV) & \\
\hline
\end{tabular}

Fonte: * McDonnel; Russel,1999 / ** Rutala; Weber, 2008.

Nos dados do Quadro 1, nota-se a inclusão de novos elementos: príons e protozoários (Coccidia e outros em forma trofozoítica e cística).

Na proposta I, Coccidia apresenta-se mais resistente do que os esporos bacterianos ${ }^{(3)}$, até então considerados a forma mais resistente de vida microbiana na classificação frente a agentes químicos desinfetantes de alto nível. Os autores não especificam os critérios utilizados para o estabelecimento da ordem de classificação dos micro-organismos, porém reconhecem que a ação de desinfetan- tes químicos contra protozoários ainda não foi largamente investigada. Na proposta II, os autores consideram que os mecanismos de resistência intrínseca aos agentes químicos são variados, mas não há justificativa clara para a posição definida para os micro-organismos Coccidia, mais resistentes do que os esporos bacterianos, na ordem de resistência ou critérios utilizados para seu estabelecimento.

A subclasse Coccidia foi apresentada na Proposta I de forma distinta das outras formas císticas e trofozoíticas de protozoários, em razão da resistência peculiar do gênero 
Cryptosporidium aos desinfetantes em uso corrente. Também se nota que em ambas as propostas a resistência desta subclasse é superior a das micobactérias, que requerem como processamento mínimo a desinfecção química de alto nível, levantando questionamentos sobre qual tipo de processamento (se desinfecção ou esterilização) seria suficiente para assegurar a reutilização dos materiais contaminados por este agente.

Considerando a importância da ordem decrescente de resistência dos micro-organismos aos agentes químicos desinfetantes, amplamente reproduzida em obras de referência ${ }^{(1-4)}$, para as práticas de controle de infecção hospitalar, incluindo o processamento de materiais, e o aparecimento de micro-organismos que até então não eram enfaticamente valorizados como de risco, identificou-se a pertinência da rediscussão das práticas de processamento de endoscópios que entram em contato com o trato digestório. Desta forma, este estudo teórico proporcionará uma reflexão sobre a necessidade de desinfecção ou esterilização de endoscópios que entram em contato com o trato digestório, com base nos riscos relacionados à subclasse Coccidia, cujos micro-organismos são resistentes aos desinfetantes químicos em uso no país e potencialmente patogênicos para pacientes imunocomprometidos.

\section{COCCIDIA}

O termo Coccidia designa uma subclasse de protozoários pertencentes ao filo Apicomplexa e à classe Sporo$z o e a^{(5)}$. A característica que melhor define este grupo de micro-organismos é o oocisto resistente, dotado de uma parede protetora ${ }^{(6)}$. Nesta subclasse, tem importância epidemiológica como agente etiológico de infecções relacionadas à assistência à saúde o gênero Cryptosporidium, em razão de suas formas císticas e trofozoíticas, que, por meio de mudanças citológicas e fisiológicas, modificariam sua resistência a agentes antissépticos e desinfetantes químicos. Outros agentes como Isospora e Cyclospora, apesar de causarem infecção em humanos, até o momento, não têm destaque na ordem de resistência intrínseca aos desinfetantes químicos ${ }^{(3-4)}$. O gênero Cryptosporidium constitui-se de parasitas intracelulares obrigatórios, cuja forma infectante é o oocisto esporulado. As principais espécies associadas a infecções em humanos são Cryptosporidium hominis e Cryptosporidium parvum ${ }^{\text {(7) }}$. São associados a infecções entéricas e a ingestão de apenas 30 oocistos é capaz de produzir infecção ${ }^{(8)}$. Há também relatos de infecções em humanos causadas por um oocisto ${ }^{(9)}$. Este dado também foi confirmado laboratorialmente pela inoculação de apenas um oocisto em camundongos imunocomprometidos ${ }^{(10)}$.

A parede de um oocisto pode ter espessura variável - as formas com parede espessa são resistentes no meio ambiente, infectantes e liberadas nas fezes, garantindo a continuidade do ciclo $^{(9)}$. Esta parede confere ao oocisto a capacidade de resistir a danos físicos e quí- micos. Também possui impermeabilidade a desinfetantes químicos comuns utilizados na prática hospitalar ${ }^{(6)}$, e ao cloro usado no tratamento da água ${ }^{(11)}$. Há estudos que reportaram ser este o mecanismo que permite que oocistos sobrevivam em ambientes úmidos por longos períodos, variando de meses a anos, conservando sua infectividade ${ }^{(6)}$

Os dois primeiros casos de infecção em humanos foram relatados, em 1976, nos Estados Unidos da América, e, em um deles, o parasita foi detectado na mucosa intestinal de um paciente imunocomprometido e, no outro caso, em uma criança com quadro de gastroenterite ${ }^{(12) .} \mathrm{A}$ infecção por Cryptosporidium é associada ao aumento de morbidade em pacientes imunocomprometidos ${ }^{(13)} \mathrm{e}, \mathrm{em}$ portadores da Síndrome da Imunodeficiência Adquirida (SIDA), a infecção pode levar à morte ${ }^{(14)}$.

Em humanos, a infecção pode ocorrer pelo contato com pessoas e animais que estão eliminando os oocistos, ingestão de água ou alimentos contaminados e inalação do oocisto em ambientes contaminados ${ }^{(5,9)}$. A possível transmissão sexual também foi documentada ${ }^{(9)}$. O desenvolvimento dos parasitas ocorre nas microvilosidades das células do trato gastrintestinal, mas também podem ser encontrados no parênquima pulmonar, vesícula biliar, ductos pancreáticos, esôfago e faringe ${ }^{(5)}$. Há relato sobre a presença do parasita aderido à superfície da membrana apical das células epiteliais gástricas, após um transplante renal(15).

Em procedimentos endoscópicos, não foram encontrados registros de transmissão iatrogênica de Cryptosporidium. Porém, considerando que o micro-organismo pode ser encontrado no intestino de pacientes imunocomprometidos, existe o risco potencial de transmissão nas colonoscopias, o que leva à necessidade de ponderar este agente no processamento de colonoscópios.

\section{COCCIDIA E AS PRÁTICAS DE PROCESSAMENTO DE MATERIAIS}

A limpeza seguida de desinfecção aparenta ser segura para impedir a transmissão da infecção associada a procedimentos de assistência à saúde, como por exemplo, os endoscópios que entram em contato com o trato digestório(16), apesar do reconhecimento da resistência desses oocistos aos desinfetantes químicos e a carência de estudos relacionados ao impacto das infecções por Coccidia no ambiente hospitalar.

Com base nas novas propostas de ordem de resistência dos micro-organismos hospitalares apresentadas, que destacaram a resistência dos micro-organismos do gênero Cryptosporidium aos agentes químicos desinfetantes, torna-se premente questionar se a prática atual de desinfecção química de alto nível seria suficiente para garantir a segurança no uso desses materiais. Quando se afirma que a subclasse Coccidia é mais resistente que um esporo, também implica afirmar que o material que a contém deva ser esterilizado, considerando suas formas de transmissão. 
Um estudo de $1990^{(17)}$, ao estabelecer recomendações para assegurar a realização de endoscopias em pacientes portadores de HIV, admitiu que os agentes utilizados para desinfecção química de endoscópios gastro-intestinais não necessitam ser esporicidas, porém a atividade contra Cryptosporidium e micobactérias não tuberculosas constituiria uma medida de proteção para pacientes imunocomprometidos submetidos a este procedimento. Os autores defendem que pacientes imunocomprometidos são susceptíveis a micro-organismos não patogênicos para hospedeiros imunocompetentes, portanto o simples enxágue de endoscópios gastrointestinais em água de torneira já implicaria em risco de infecção, tanto para Cryptosporidium (sem referência a estudos primários) quanto para micobactérias não tuberculosas. A esterilização destes materiais seria recomendada como medida de proteção para esses pacientes, entretanto, os autores listam estratégias para realização segura do processamento dos endoscópios, entre elas: a limpeza rigorosa, a observância aos tempos mínimos recomendados para a desinfecção química, as quais poderiam reduzir o número de Cryptosporidium e micobactérias não tuberculosas para uma quantidade segura e o último enxágue em água esterilizada ou com álcool a $70 \%$ para eliminação da contaminação carreada pela água da torneira.

As estratégias apresentadas são questionáveis, pois não consideraram que um pequeno número ou até mesmo um oocisto é suficiente para causar a infecção em indivíduos susceptíveis. Além disso, os autores não apresentaram nenhum dado experimental ou estudo primário que caracterizasse a quantidade segura de Cryptosporidium para pacientes imunocomprometidos.

Outro estudo de $1999^{(16)}$ testou formulações comerciais à base de Peróxido de Hidrogênio, Ácido Peracético, Hipoclorito de Sódio, Fenol, Quaternário de Amônia, Glutaraldeído 2\% e Ortoftaldeído contra uma suspensão contendo $10^{5} / 10^{6}$ oocistos do Cryptosporidium parvum. $\mathrm{O}$ único produto que foi capaz de reduzir acima de 3 logs de oocistos foi o Peróxido de Hidrogênio em concentrações de 7,5\% e 6,0\% (produtos ainda não disponíveis em nosso meio), a uma temperatura de $20^{\circledR} \mathrm{C}$, em um tempo de 20 minutos de exposição. Quando utilizadas concentrações menores ou menor tempo de exposição ao produto, houve ineficácia em seu desempenho.

No mesmo trabalho, os autores estudaram a sobrevivência do oocisto no ambiente e constataram uma redução da infectividade em superfícies secas e à temperatura ambiente - cerca de 2,9 logs em 30 minutos.

Para os autores, o resultado não evidenciou necessidade de mudança nas práticas de processamento de endoscópios com base nos argumentos de que a limpeza do material removeria em torno de $10^{4}$ micro-organismos e que a viabilidade do Cryptosporidium parvum é reduzida em função do tempo, quando em superfícies secas ${ }^{(16)}$.

Embora as publicações afirmem que, até o momento, não haveria justificativa para mudanças nas práticas de processamento de endoscópios, esta posição é controversa pelas evidências de desinfetantes químicos de alto nível, usualmente empregados na desinfecção de alto nível dos endoscópios, glutaraldeído, ácido peracético e ortoftalaldeído - serem ineficazes contra a completa inativação de Cryptosporidium ${ }^{(16)}$, o que requer a utilização de Peróxido de Hidrogênio a $6 \%$ ou $7,5 \%$, ainda não disponíveis no Brasil. Sendo assim, este estudo conduz à aceitação da ordem de resistência intrínseca dos micro-organismos apresentada na Proposta II, em razão da desinfecção de alto nível ser suficiente, desde que utilizado um desinfetante eficaz. Entretanto, tal posição, requer a discussão de dois aspectos visando ao controle das infecções por Cryptosporidium.

O primeiro consiste na legislação brasileira. A Resolução da Diretoria Colegiada (RDC) número $35^{(18)}$, de 16 de agosto de 2010, define os micro-organismos-testes para avaliação da ação antimicrobiana. Para um desinfetante químico de alto nível, a RDC preconiza que o produto seja capaz de eliminar os seguintes micro-organismos: Staphylococcus aureus, Salmonella choleraesuis, Escherichia coli, Pseudomonas aeruginosa, Trichophyton mentagrophytes, Candida albicans, Mycobacterium smegmatis, Mycobacterium bovis, Mycobacterium massiliense, Bacillus subtilis e Clostridium sporogenes. De uma forma menos rigorosa, a legislação americana, adotando a metodologia da Association of Analytical Communities (AOAC internatio$n a l)^{(19)}$, inclui apenas Staphylococcus aureus, Salmonella choleraesuis, Pseudomonas aeruginosa, Trichophyton mentagrophytes, Mycobacterium smegmatis, Mycobacterium bovis.

Conforme constatado, na referida RDC e também na metodologia da $A O A C$ international, não há referência à subclasse Coccidia, quando se estabelecem os microorganismos utilizados na avaliação de desinfetantes químicos para artigos semicríticos. O fato é preocupante, pois os produtos atualmente em uso para desinfecção química de alto nível, mesmo que aprovados, não foram desafiados contra Coccidia. Em vista do uso desses produtos para a desinfecção química de endoscópios, torna-se necessária uma rediscussão dos microorganismos propostos pela RDC 35 para a aprovação de desinfetantes químicos para artigos semicríticos com inclusão do gênero Coccidia, particularmente Cryptosporidium. Além disso, considera-se necessário que os fabricantes de desinfetantes de alto nível para uso em endoscópios especificassem a eficácia contra Cryptosporidium. 
O segundo aspecto consiste na esterilização dos endoscópios. Uma pesquisa sobre a infestação em portadores de HIV constatou um número elevado de casos entre indivíduos do sexo masculino com idade entre 20 e 50 anos e sintomas diarreicos. Os autores fazem inferências de que o problema pode ser de difícil controle, o que determinaria, consequentemente, a necessidade do estabelecimento de medidas que venham a impedir a disseminação de Cryptosporidium $^{(20)}$. Mesmo assim, apesar da publicação da Proposta I e II em veículos de ampla disseminação no mundo, posicionando este agente como mais resistente do que a micobactéria, não houve mudanças nas recomendações dos guidelines que orientam o processamento de endoscópios. As justificativas mais prováveis seriam: a baixa expressão epidemiológica da transmissão iatrogênica do Cryptosporidium e a restrita opção de desinfetante químico de alto nível capaz de eliminá-lo, que por enquanto é o Peróxido de Hidrogênio a $6 \%$ ou 7,5\%, ainda não disponível no Brasil.

Atualmente há equipamentos destinados à esterilização de endoscópios, como o System $1^{\circledR(21)}$, desenvolvido pela empresa Steris $^{\circledR}$, que utiliza ácido peracético, com tempo de esterilização de 12 minutos a $50-56{ }^{\circ} \mathrm{C}$ e ciclo completo de 30 minutos. Ressalta-se que a segurança na utilização desse sistema ou de qualquer outro equipamento está condicionada às devidas validações empregando o gênero Coccidia como micro-organismo teste, uma vez que um estudo experimental demonstrou ineficácia do ácido peracético $0,2 \%$ Steris $^{\circledR}$ a $23-25{ }^{\circ} \mathrm{C}$ por 12 minutos, na inativação do Cryptosporidium ${ }^{(16)}$.

Além da discussão desses aspectos, há também a necessidade de identificação de falhas, padronização de normas e rotinas para o processamento de endoscópios e a implantação da educação permanente dos profissionais que atuam nos serviços de endoscopia, visando ao controle da disseminação de Cryptosporidium e à segurança da assistência prestada(22).

\section{REFERÊNCIAS}

1. Spaulding EH. Chemical disinfection of medical and surgical materials. In: Block SS. Disinfection, sterilization and preservation. Philadelphia: Lea \& Febiger; 1968. p. 517-31.

2. Favero MS, Bond WW. Chemical disinfection of medical and surgical materials. In: Block SS. Disinfection, sterilization, and preservation. 4th ed. Philadelphia: Lea \& Febiger; 1991. p. 617-41.

3. McDonnell G, Russell D. Antiseptics and disinfectants: activity, action, and resistance. Clin Microbiol Rev. 1999;12(1):147-79.

4. Rutala WA, Weber DJ, HICPAC. Guideline for disinfection and sterilization in healthcare facilities, 2008. Atlanta, GA: US Department of Health and Human Services; 2008. Disponível em: http://www.cdc.gov/ncidod/dhqp/pdf/guidelines/disinfection_nov_2008.pdf.

\section{CONCLUSÃO}

Este estudo teórico proporcionou uma reflexão sobre a resistência intrínseca da subclasse Coccidia, particularmente o gênero Cryptosporidium, considerado como um agente potencialmente patogênico para pacientes imunocomprometidos e suas repercussões na prática assistencial.

Evidenciou-se que a subclasse Coccidia é mais resistente que as micobactérias e que os desinfetantes químicos de alto nível usuais não são capazes de eliminá-la, exceção feita ao Peróxido de Hidrogênio $6 \%$ a 7,5\%. Embora a Proposta I posicione a subclasse Coccidia como mais resistente do que os esporos bacterianos, o que exigiria métodos diferenciados de esterilização, um estudo experimental demonstrou a sensibilidade do Cryptosporidium a um desinfetante químico de alto nível, conduzindo a aceitação da Proposta II.

Apesar de a literatura não ressaltar a necessidade de mudança nas práticas atuais de processamento de endoscópios, quando previamente bem limpos, há contradições com a lógica de que a presença de um único oocisto de Cryptosporidium seria potencialmente capaz de causar a doença em indivíduos imunocomprometidos. Portanto, estes micro-organismos devem ser incluídos no rol daqueles indicados para testes de desafio para desinfetantes químicos na ocasião de sua aprovação para fins de registro em órgãos nacionais e internacionais.

Recomenda-se que os estabelecimentos de assistência à saúde adotem medidas de controle de qualidade da água utilizada, pelo menos para o último enxágue dos endoscópios. Faz-se urgente a disponibilização de desinfetantes químicos de alto nível eficazes contra Cryptosporidium, assegurando a utilização das precauções padrão no processamento de colonoscópios.

5. Vitor RWA. Protozoa. In: Neves DP, editor. Parasitologia humana. 11a ed. São Paulo: Atheneu; 2005. p. 33-5.

6. Belli SI, Smith NC, Ferguson DJ. The coccidian oocyst: a tough nut to crack! Trends Parasitol. 2006;22(9):416-23.

7. Hunter PR, Hadfield SJ, Wilkinson D, Lake IR, Harrison FC, Chalmers RM. Subtypes of Cryptosporidium parvum in humans and disease risk. Emerg Infect Dis. 2007;13(1):82-8.

8. DuPont $\mathrm{HL}$, Chappell $\mathrm{CL}$, Sterling CR, Okhuysen PC, Rose JB, Jakubowski W. The infectivity of Cryptosporidium parvum in healthy volunteers. N Engl J Med. 1995;332(13):855-9.

9. Melhem MSC, Almeida TTC. Criptosporidiose e microsporidiose. In: Focaccia R, editor. Veronesi: tratado de infectologia. 3a ed. São Paulo: Atheneu; 2005. p. 1475-83. 
10. Yang S, Benson SK, Du C, Healey MC. Infection of immunosuppressed C57BL/6N adult mice with a single oocyst of cryptosporidium parvum. J Parasitol. 2000;86(4):884-7.

11. Centers for Disease Control and Preventions (CDC). Cryptocryptosporidiosis [Internet]. [cited 2008 Apr 16]. Available from: http://www.cdc.gov/crypto/

12. Falchi RLR. Contaminação por protozoários potencialmente patogênicos ao homem na água de diferentes pontos da Laguna dos Patos, Rio Grande, RS [dissertação] Pelotas: Instituto de Biologia, Universidade Federal de Pelotas; 2006.

13. Farthing MJ. Treatment options for the eradication of intestinal protozoa. Nat Clin Pract Gastroenterol Hepatol. 2006;3(8):436-45.

14. Barta JR, Thompson RC. What is cryptosporidium? Reappraising its biology and phylogenetic affinities. Trends Parasitol. 2006;22(10):463-8.

15. Franco A, Rocamora N, Merino E, Paya A. Cryptosporidiosis: a rare infection in renal transplantation. Nefrologia. 2006;26(6):753-4.

16. Barbee SL, Weber DJ, Sobsey MD, Rutala WA. Inactivation of Cryptosporidium parvum oocyst infectivity by disinfection and sterilization processes. Gastrointest Endosc. 1999;49(5):605-11.
17. Hanson PJ. AIDS: practising safe endoscopy. Baillieres Clin Gastroenterol. 1990;4(2):477-94.

18. Brasil. Ministério da Saúde; Agência Nacional de Vigilância Sanitária. RDC n. 35, de 16 de agosto de 2010. Dispõe sobre o Regulamento Técnico para produtos com ação antimicrobiana utilizados em artigos críticos e semicríticos [Internet]. Brasília; 2010 [citado 2010 dez. 16]. Disponível em: http:// www.brasilsus.com.br/legislacoes/rdc/105102-35.html

19. Tomasino S. Official methods of analysis. 18th ed. revision 3. Gaithersburg: Association of Official Analytical Chemists; 2010. Disinfectants.

20. Ribeiro PC, Pile E, Queiroz MMC, Queiroz MMC, Norberg AN, Tenório JRO. Cryptosporidiosis occurrence in HIV+ patients attended in a hospital, Brazil. Rev Saúde Pública. 2004;38(3):469-70.

21. Steris. SYSTEM $1^{\circledR}$ Sterile Processing System [Internet]. 2010 [cited 2010 Dez 2]. Available from: http://www.steris.com/ documents.cfm?id=M1868ES

22. Anders PS, Tipple AFV, Pimenta FC. Kits para aerossol em um serviço de saúde: uma análise microbiológica após reprocessamento. Rev Esc Enferm USP. 2008;42(2):276-81.

\section{Agradecimentos}

Ao Conselho Nacional de Desenvolvimento Científico e Tecnológico (CNPq), pelo apoio financeiro. 